\title{
Greek Teachers' Views about Their Organizational Commitment to Primary School
}

\author{
Iordanidis G., Tsakiridou H. , Sagiadinou G. \\ Department of Primary Education, University of Western Macedonia, Florina, Greece \\ *Corresponding author: etsakir@uowm.gr \\ Received July 03, 2014; Revised July 25, 2014; Accepted July 28, 2014
}

\begin{abstract}
The characteristics of commitment to school, students, teaching, career and profession along with a body of knowledge, skills, abilities and behaviors are those which compose the organizational commitment of teachers. The purpose of the present study is to investigate teachers' views about their organizational commitment to primary school. More specifically, the study aims to record teachers' views regarding seven teamwork characteristics: communication, leadership, guidance, feedback, supportive behavior, collaboration and trust. The sample was consisted of 245 primary education teachers. The results show that teachers recognize the importance of all the seven factors regarding teamwork characteristics. Moreover, teachers' views are significantly influenced by their age and their teaching experience.
\end{abstract}

Keywords: teachers' organizational commitment, teamwork, teachers' experience

Cite This Article: Iordanidis G., Tsakiridou H., and Sagiadinou G., "Greek Teachers' Views about Their Organizational Commitment to Primary School.” American Journal of Educational Research, vol. 2, no. 8 (2014): 603-611. doi: 10.12691/education-2-8-8.

\section{Introduction}

Teachers' interpersonal relationships and the collaboration practices they develop at school level, as well as the way that the labor status affects these relationships are subjects that have so far been examined by researchers and scientists. Nowadays, due to the diversity and complexity of situations, the teacher's role has become extremely critical. In order to perform their complex task successfully, the teachers' commitment related to their job satisfaction seems to be vital [48]. Teachers socialize professionally within the school unit [40], which means that they become familiar with the values, norms and necessary professional behavior, which is appropriate for the school organization, and are able to share reciprocally the values, common goals with their colleagues, as well as acquire a feeling of belonging to that particular school unit and both give and, in turn, gain value themselves from the school organization, which in turn, results in giving and taking value in themselves inside the school as an organization.

The successful operation of school organizations depends not only on qualitative and cooperative teachers, but also on the stability of the teaching staff in a certain school unit. The staff stability factor, as well as the frequent mobility of the teaching staff, minimizes the school community cohesion. Furthermore, it affects adversely the school staff and the students' performance, while it deprives the school administration of the ability to carry out creative activities. Teachers' mobility due to transfer or secondments does not only affect teachers' moral negatively, but it also affects negatively students' performance as well as school's effectiveness in general [42]. Studies [12] have demonstrated differences in the organizational commitment between permanently employed and hourly-paid teachers, whereas other researches [50] have indicated that school staffing with part-time employed teachers or with teachers working on a reduced working hour basis has controversial learning outcomes.

It is widely recognized that in a constantly changing environment, the working relationships among teachers will also be susceptible to changes. The aim of this paper is to investigate whether the teachers' labor status, gender, age, specialization, total years of teaching experience, as well as the total years spent in a particular school unit play a role in strengthening or weakening, respectively, the intensity of teachers' organizational commitment and collective work.

\section{Literature Review}

\subsection{Teachers' Organizational Commitment and Teamwork}

A great deal of attention has been given to the study of commitment to the organization [35]. Previous research on organizational commitment has been criticized for failing to investigate commitment as a construct distinct from other psychological concepts [36]. For instance, studies have often measured commitment as a combination of belief in an organization's goals and values, a willingness to exert considerable effort on behalf of the organization, 
and a desire to maintain organizational membership [34]. Whereas the first component is focused on the psychological basis for attachment, the latter two are likely consequences of commitment, not antecedents. One's commitment to an organization can result from value congruence, financial investments, effective reward and control systems, or a simple lack of opportunity to move $[3,32,38,41]$. Previous failures to develop clear operational definitions of the basis for commitment may have contributed to the lack of strong findings explicating the components of commitment and linking these to outcomes such as absenteeism, effectiveness, and prosocial behaviors [2].

Like many constructs in organizational psychology, however, commitment has been conceptualized and measured in various ways [29]. In a model of commitment developed by [28], there were three approaches labelled 'affective', 'continuance' and 'normative' commitment. Although common to these approaches is a link between the employee and organization that decreases the likelihood of turnover, it is clear that the nature of that link differs. Employees with strong affective commitment remain because they want to, those with strong continuance commitment because they need to, and those with strong normative commitment because they feel they ought to do so.

However, two issues that are important for further refinement of the $[28,29]$ measures are the generalizability of the model in a 'micro' sense, and the relationship between the commitment constructs and recently developed work attitudes that appear to tap at least a part of the same conceptual space [20]. Micro generalizability refers to the validity of the model within sub-populations in the roader Western culture in which it was developed. Historically, research on organizational commitment within the [29] paradigm has focused on full-time paid organizational members. But, not all organizational members have these characteristics. A growing number of organizations are employing part-time, temporary and contract workers [30], and some organizations include volunteers. Concerning the commitment of members of these sub-populations, research is largely lacking, though some initial steps have been taken. Finally, several new work-related attitudes have been introduced in the literature that seemingly tap similar conceptual space or otherwise challenge the validity of the [29] model [11,24].

Teacher working conditions constitute an important factor which affects teachers' commitment. The more stable the teachers' presence is, the more they are committed to the school, whereas they get to know their colleagues, students and the broader school and local community better [12]. Studies [33,40] have demonstrated a statistically significant difference in organizational commitment and satisfaction from work, between the permanently employed and hourly-paid teachers, since the motivation in each individual employee group varies significantly. Teachers who serve on a fixed-term basis experience higher levels of job insecurity [22], compared to the permanently employed teachers.

On the other hand, research on teams and teamwork in schools include few studies focused on teamwork skills that influence how effective an individual member may be as part of a team. The model of teamwork used in this study views teamwork from the perspective of team process skills [7]. Team skills include communication, team orientation, team leadership, monitoring, feedback, backup behavior, and coordination.

This paper focuses on the concept of commitment in terms of teachers' involvement in the school, as well as regarding the sense of teamwork. It should be highlighted that the sense of commitment growing in teachers working in a school organization, is marked by the organizational characteristics of teamwork, which are: communication, trust, coordination, leadership, support of the educational work and feedback.

Communication involves the exchange of information between a team member and other members of the team in the prescribed manner, using proper terminology. Communication is the linking mechanism among the other components of teamwork. Coordination refers to the team members executing their activities in a timely and integrated manner. It indicates that the performance of some team members influences the performance of other team members. Trust has been acknowledged as an essential element in social interaction [9]. Team transactions characterized by interpersonal trust promote an environment in which individuals feel free to express their ideas, engage in problem solving, and resolve differences of opinion [8]. Trust in teams and teamwork in schools are effected by levels of interpersonal trust that are linked, in turn, to social and leadership relationships, organizational effectiveness, school climate and health, and student achievement [4,14,15,16,46,47,49]. Team leadership includes providing direction, structure, and support for other team members. It does not necessarily refer to a single individual with formal authority over others. In other words, team leadership can be shown by several team members. Monitoring refers to observation and awareness of activities and performance of other team members. It implies that the individual team member is competent, and is capable of providing feedback and backup behavior. Feedback involves the giving, seeking, and receiving of information.

It is specifically worth mentioning that the decisive role of good interpersonal relationships among teachers is already recognized since the 1970s [26]. Good interpersonal relationships are considered to be a basic source of internal reward, which becomes meaningful due to the lack of strong external rewards, as far as the teaching profession is concerned, and due to problems often arising in relationships between students and teachers [51]. Modern researches on teachers' work life are based on the assumption that colleague relationships help teachers cope with the multiple demands of their profession, reduce stress and increase their satisfaction and "well-being" in a more effective way [1].

Collegiality requires provision of training and assistance to teachers, in order to become familiar with collaborative practices which foster mutual trust, as well as material supports [19]. However, most teachers believe that they should not be concerned with what their colleagues do, which results in older and experienced teachers with well documented views on effective teaching avoiding offering their advice to novice teachers, unless they are asked to [19].

Reference [18] mentions that the leadership of the team of teachers determines the framework of teachers' work, including activities which involve teachers' interaction and 
collaboration. Leadership supports cohesion, coherence, free expression of feelings, mutual trust among members and open communication. Team members have clear-cut roles, acceptable, mutual school-oriented targets and goals [18]. Furthermore, a group of teachers works well, when teachers discuss about teaching, watch each other teach, plan, study and assess educational material reciprocally and support each other, in order to improve their teaching skills, within a climate of mutual trust, true communication and collaboration. [10]. Collaboration is one of the most essential components in the composition of effective teams [5]. The most important problems occurring are related to collaboration and uneven engagement in the teachers' team. A greater extent of engagement implies commitment to teamwork. The effort to achieve the aims and goals of the school organization includes coordination and communication, sharing knowledge and strategies.

An integral feature of the teachers' team beyond the mutual acceptance of values and goals is also the formal, informal and personal communication, sharing of ideas and information, i.e. social interaction. Open communication increases expectations for greater engagement and strengthens the sense of involvement, the feeling of belonging in the school's teacher board, and the feeling of collectivity and collegiality [6]. It is believed that collegiality fosters the development of teachers beyond personal expectations or dependence from external specialists, so that they reach a point where they learn from each other and develop their expertise on a mutual basis.

\section{Research}

\subsection{Aim- Method}

The aim of this study is to investigate primary education teachers' views on their collective organizational commitment to school. In order to record the views of teachers, a questionnaire was selected which was also used in the research of reference [25]. This questionnaire focuses on the teachers, rather than on the school organization in general. Reference [25] has used it, because it refers to the commitment of teachers to teamwork, from the teachers' team point of view. It consists of 21 items that are answered applying the Likert scaling method and is divided into seven subcategories, namely the characteristics of teamwork. Each subcategory includes three items, in the following order: communication, leadership, guidance, feedback, supportive behavior, collaboration and trust. The questionnaire used a Likert-type scale, since its data can undergo a complex statistical analysis. Likert scale employs a series of numbers-scores as responses-options, e.g. 1, 2, 3, 4, 5, 6, matching responses of the "Disagree"/"Agree" type, distributed in a five-level format, namely: 1- Strongly disagree, 2-Disagree, 3-neither disagree nor agree, 4- neither disagree nor agree, 5-Agree, 6- Strongly agree. SPSS was used for the statistical analysis that followed. In order to investigate whether there were any statistically significant differences in the views of teachers regarding teamwork characteristics (communication, leadership, guidance, feedback, supportive behavior, collaboration and trust) and their individual characteristics (gender, age, specialization, total years of teaching experience, years spent in a particular school unit and employment status), the statistical tests of independent samples t-test and ANOVA were used with the responses in the group of questions regarding communication, leadership, guidance, feedback, supportive behavior, collaboration and trust as the dependent variables, and the teachers' individual characteristics (gender, age, total years of teaching experience, employment status) as the independent variables.

\subsection{Sample}

The sample was consisted of 245 (176 females and 69 males) primary education teachers in the Ionian Islands' Region. The total number of the primary education teachers in the Region of Ionian Islands is 1027, thus the sample represents the $23.85 \%$ of the total population of the primary education teachers in this Region. Due to reasons of economic-technical nature and ease of access to the school units, random sampling was the sampling method selected [29]. The selected school units involved all statutory posts from urban, semi-urban and rural areas of Zakynthos (28.5\%), Corfu (50.6\%), Cephalonia (12.7\%) and Leukada (8.2\%) (Table 1). Regarding to their teaching experience in primary schools, $18.4 \%$ of the teachers had already up to 10 years of experience, the $24.8 \%$ of the teachers had 11 to 20 years, the $46.4 \%$ of the teachers had 21 to 30 years of teaching experience and the $10.4 \%$ of the teachers had more than 30 years of experience (Table 2). The average age of the teachers was 41 years with a standard deviation of 8.7 years. The younger teacher of the sample was 25 years old and the oldest teacher was 56 years old.

Table 1. Sample size per island

\begin{tabular}{|c|c|c|}
\hline Island & $\mathrm{N}$ & $\%$ \\
\hline Corfu & 124 & 50.6 \\
\hline Zakynthos & 70 & 28.5 \\
\hline Cephalonia & 31 & 12.7 \\
\hline Leukada & 20 & 8.2 \\
\hline Total & 245 & 100 \\
\hline
\end{tabular}

Table 2. Teachers' years of experience

Table 2. Teachers' years of experience
\begin{tabular}{|c|c|c|}
\hline Years & $\mathrm{n}$ & $\%$ \\
\hline$\leq 10$ & 45 & 18.4 \\
\hline $11-20$ & 61 & 24.8 \\
\hline $21-30$ & 114 & 46.4 \\
\hline$>30$ & 25 & 10.4 \\
\hline Total & 245 & 100 \\
\hline
\end{tabular}

\subsection{Results}

The characteristics of teamwork (communication, leadership, guidance, supportive behavior and trust), each one described separately, and the impact of teachers' individual characteristics (age and total years of teaching experience) on them are being described as follows. It is worth mentioning that there were no statistically significant differences in teachers' views on all the characteristics of teamwork according to their gender or their employment status.

\subsubsection{Communication}

The factor of communication comprises of the first three items of the questionnaire. The Cronbah's a for the 
communication factor reached the acceptable level of 89.4\%. School teachers often talk about the school problems. School teachers are willing to inform everybody of their colleagues about everything they know. The average agreement among teachers in the category of communication was 5 , with a standard deviation of 0.96 (Table 3). It is obvious that teachers seem to be particularly satisfied from the communication with their colleagues at school level. More specifically, in the first statement, "Communication among school teachers is easy and pleasant" the majority, namely $72 \%$ of all teachers, answered that they mostly agree to it, whereas $2.7 \%$ strongly disagreed. Regarding the second statement, "School teachers talk often about the school problems" most teachers, namely $63.33 \%$, have expressed their agreement, whereas the opposite view was expressed by $7.34 \%$ of them. The third item of the questionnaire, "School teachers are willing to inform everyone of their colleagues about everything they know" is a statement to which $78 \%$ of all teachers strongly agree, whereas almost $21 \%$ of them neither agree, nor disagree.

Table 3. Descriptives for each of the seven teamwork characteristics

\begin{tabular}{|c|c|c|}
\hline Table 3. Descriptives for each of the seven teamwork characteristics \\
\hline Factor & M & SD \\
\hline Communication & 5.00 & 0.96 \\
\hline Leadership & 4.52 & 0.96 \\
\hline Guidance & 4.42 & 1.16 \\
\hline Feedback & 4.51 & 1.07 \\
\hline Supportive Behaviour & 4.97 & 1.03 \\
\hline Collaboration & 4.79 & 0.97 \\
\hline Trust & 5.00 & 0.92 \\
\hline
\end{tabular}

Regarding the communication factor, statistically significant differences found between the age groups of teachers $\left(\mathrm{F}_{3,121}=3.152\right.$, $\left.\mathrm{p}<0.001\right)$. In particular, host hoc analysis using LSD test, indicated statistically significant differences between the age groups of teachers. More specifically, teachers over 51 years old seemed to experience the better communication conditions, scoring 5.31, with a standard deviation of 0.95 . A less indicative perception of communication seems to be experienced by teachers of 41 to 51 years of age, who scored 4.95, with a standard deviation of 0.84 . A slight difference with respect to communication among teachers can be noticed in the ages ranging from 31 to 40 years, who scored 4.94, with a standard deviation of 0.90 . However, the lowest level of agreement concerning the communication factor was traced in the mean score of teachers aged from 20 to 30 years, who consider the communication between school teachers to be 4.41 , with a standard deviation of 1.09 . Therefore, we can see that older age groups of teachers believe that there is a higher level of communication in the school than what younger teachers believe (Table 4).

Moreover, the total years of teaching experience seem to have an impact on the existence or absence of adequate communication between teachers. More specifically, teachers with a total teaching experience of 21 years seem to communicate more with their colleagues, scoring 5.16, with a standard deviation of 0.90 . Furthermore, teachers with 11 to 20 years of teaching experience support the aforementioned statement, scoring 4.82 with a standard deviation of 0.80 , whereas teachers with up to 10 years of teaching experience scored 4.6 with a standard deviation of 1.03, believing that communication with colleagues is satisfactory. The difference noticed between the total years of teaching experience and perceived communication between colleagues is statistically significant $\left(\mathrm{F}_{2,135}=4.670, \mathrm{p}<0.001\right)$. It becomes apparent that teachers having more than 21 years of teaching experience claim to be more satisfied with the communication developed with their colleagues (Table 5).

\subsubsection{Leadership}

The factor of leadership consisted of three statements with Cronbach's a $=87.3 \%$. The mean level of agreement among teachers with reference to the aforementioned statements is 4.52, with a standard deviation of 0.96 (Table 3). More specifically, regarding the statement that "School teachers are willing to participate in school activities" the vast majority of teachers mostly agreed by $62 \%$, whereas a negative opinion regarding participation in school activities was expressed only by $5 \%$. With respect to the second statement, namely that "School teachers show high levels of job satisfaction", half of the teachers (50\%) strongly agreed to the aforementioned hypothesis, whereas a significant amount of teachers, namely 39.3\%, neither agreed, nor disagreed. Regarding the third statement of this category, that "School teachers give priority to school goals", teachers agreed by $57.3 \%$, whereas only $4.6 \%$ of them appeared not to give priority to goals set by the school.

The statements related to leadership are significantly influenced by the teachers' total years of teaching experience $\left(\mathrm{F}_{2,135}=3.520, \mathrm{p}<0.001\right)$. LSD test revealed that more experienced teachers reported more satisfaction regarding the aforementioned statements. In particular, teachers with more than 21 years of teaching experience reported acquiring more satisfaction arising from the school goals, scoring 4.75, with a standard deviation of 0.84 , whereas teachers having from 11 to 20 years of experience reported less satisfaction, scoring 4.33, with a standard deviation of 0.86 . Finally, less experienced teachers, those who have a teaching experience up to 10 years, expressed less satisfaction from leadership, scoring 4.32, with a standard deviation of 1.06 (Table 5).

\subsubsection{Guidance}

The questionnaire filled in by the teachers, included three statements regarding guidance factor provided among teachers. The Cronbach's a for the guidance factor reached the acceptable level of $91.2 \%$. The mean score of agreement among teachers regarding the category of guidance was 4.42 and the standard deviation regarding the statements about guidance among colleagues amounts to 1.16 (Table 3). More specifically, regarding the statement "School teachers make sure their colleagues work with adequate teaching, supervisory and learning material" $53 \%$ of the research sample strongly agreed, whereas $11 \%$ of them seemed to believe the opposite. Regarding the next statement "School teachers encourage their colleagues to face new teaching challenges" most teachers seem to agree, by $54 \%$, whereas $9.3 \%$ of them expressed the opposite point of view. Finally, the vast majority of teachers strongly agreed to the statement that "School teachers care about the needs of their colleagues", by $57 \%$, whereas only $9.3 \%$ of them seemed not to care about the needs of their colleagues.

Regarding the statements which refer to the guidance provided to teachers by their colleagues, it seems that the total years of teaching experience have a statistically 
significant impact on it $\left(\mathrm{F}_{2.135}=3,413, \mathrm{p}<0.001\right)$. LSD test showed that more experienced teachers believe that the existence of guidance among colleagues is more intense. More specifically, teachers with more than 21 years of teaching experience reported a satisfaction score of 4.67 , with a standard deviation of 1.087, whereas teachers with teaching experience ranging from 11 to 20 years reported a satisfaction score of 4.32, with a standard deviation of 1.07. Finally, teachers with up to 10 years of teaching experience reported satisfaction from guidance provided by their colleagues scoring 4.13 , with a standard deviation of 1.17 (Table 5).

\subsubsection{Feedback}

The category of feedback includes three questionnaire items with Cronbach's a $=88.5 \%$. The mean score of teachers expressing their agreement-disagreement to the aforementioned statements was 4.51, with a standard deviation of 1.07 (Table 3). It is, thus, generally accepted that teachers appear to be satisfied enough with respect to the feedback provided between their colleagues. More specifically, regarding the statement that "School teachers respond to their colleagues' need for feedback", 61\% of the teachers appear to strongly agree to the aforementioned statement, whereas just $5.3 \%$ of the total teacher population expressed the opposite opinion. Furthermore, with respect to the statement that "School teachers apply the instructions of their colleagues for their self-improvement" exactly $50 \%$ of all teachers identified themselves with that hypothesis, while only $8 \%$ express the contrary disagreeing strongly. Furthermore, regarding the statement that "School teachers provide useful instructions to their colleagues", $55.3 \%$ of the population sampled strongly agreed, whereas 6\% strongly disagreed as far as the provision of useful instructions to colleagues is concerned.

It is worth mentioning that teachers' views about the feedback factor are not significantly differentiates according to teachers' age or their years of experience.

\subsubsection{Supportive Behavior}

Three statements represent the supportive behavior factor. The Cronbach's a for this factor reached the acceptable level of $83.4 \%$. The mean score of agreement among teachers in the supportive behavior category was 4.97, with a standard deviation of 1.03 (Table 3). It is generally acknowledged that teachers agree completely to the statements of the questionnaire which highlight the supportive behavior between colleagues. More specifically, the vast majority of teachers, almost $75 \%$, reported as far as the statement "School teachers complement each other, when a colleague is unable to overcome a difficulty" is concerned that they mostly agree to the view expressed, whereas only 5.3\% disagreed completely. Regarding the statement "School teachers are willing to offer their help, when they are asked to" $76 \%$ of all teachers agreed, which is a significant amount, compared to $3.3 \%$ of teachers who believed that teachers are not willing to offer their help, when they are asked to. Regarding the hypothesis that "School teachers provide their help to those who need it" a high percentage of teachers, namely $79 \%$, claimed that they completely agree, whereas just 5.3\% expressed the opposite point of view.
It should be highlighted that regarding the issue of the supportive behavior, a divergence of views is to be noticed significantly depending on the teachers' age (F $3.121=$ 4.355, $\mathrm{p}<0.001)$. LSD test revealed that older teachers are more satisfied from their colleagues' supportive behavior towards them. Teachers who are older than 51 years claim to be mostly satisfied from the support provided to them by their colleagues, scoring 5.56, with a standard deviation of 0.63 , whereas, accordingly, the average number of teachers aged from 31 to 40 years reported that there is a collaborative spirit among their colleagues, scoring 5.08, with a standard deviation of 1.09 . The age group concerning the 41-50 year-old teachers agreed to the statements of the supportive behavior category, scoring 5.03, with a standard deviation of 0.92 . However, the age group involving teachers aged between 20 and 30 years seems to agree less to the statement regarding supportive behavior, agreeing to the existence of this issue by 4.41 , with a standard deviation of 1.11 . It is generally accepted that teachers perceive differently the supportive behavior of their colleagues, depending on which age group they belong to (Table 4).

The difference noticed between the total years of teaching experience and the supportive behavior of their colleagues towards them is statistically significant $\left(\mathrm{F}_{2.135}\right.$ $=5.867, \mathrm{p}<0.001)$. LSD test revealed that in terms of supportive behavior, teachers with more years of teaching experience seem to experience this issue to a much greater extent than teachers with less years of teaching experience. More specifically, teachers with a total of 21 years of teaching experience and more agreed to the statements about support, scoring 5.27, with a standard deviation of 0.81 , and teachers falling in the category of 11 to 20 years of teaching experience reported satisfaction, scoring 4.99, with a standard deviation of 0.90 . The group of teachers with up to 10 years of total teaching experience marked their satisfaction reaching 4.62, with a standard deviation of 1.14 (Table 5).

\subsubsection{Collaboration}

There were also three questions about collaboration between teachers. The Cronbach's a reached the acceptable level of $82.3 \%$. The mean score of agreement among teachers in the category of collaboration was 4.79, with a standard deviation of 0.97 (Table 3). More specifically, regarding the statement "School teachers assist their colleagues in being more efficient", the majority of the teachers, namely $73 \%$, strongly agreed, compared to a 5\% who expressed the opposite point of view. At the same time, regarding the statement "School teachers perform their duties efficiently in consultation with the rest of their colleagues" a high percentage of teachers seemed to agree, namely $62 \%$, with only $4 \%$ reporting disagreement. Furthermore, the statement "School teachers collaborate in order to achieve the school goals" seemed to be strongly supported by $68 \%$ of all teachers, with only $4 \%$ contradicting it.

The approaches to the issue of collaboration significantly differ in terms of the teachers' age $\left(\mathrm{F}_{3,121}=\right.$ 2.779, $\mathrm{p}<0.001)$. LSD test revealed that the older age groups of the teachers believe that collaboration among colleagues is a prevailing aspect. Notably, teachers aged over 51 years claimed to be mostly satisfied from the existence of collaboration between their colleagues, 
scoring 5.10, with a standard deviation of 0.96 . Teachers of aged from 41 to 50 years claimed to be less satisfied with their collaboration, scoring 4.87, with a standard deviation of 0.87 . The age group ranging from 31 to 40 years reported relative satisfaction from their collaboration, scoring 4.86, with a standard deviation of 1.09. Finally, the mean score of teachers of the age group of between 20 to and 30 years who reported that they collaborated with their colleagues scoring 4.29 , with a standard deviation of 0.93 (Table 4).

Regarding the questions about collaboration among teachers, statistically significant differences were also recorded regarding the total years of teaching experience $\left(F_{2,135}=3.929, p<0.001\right)$. The LSD test showed that teachers with longer teaching experience seem to report that collaboration prevails in their colleague relationships to a much greater extent, compared to teachers with less teaching experience. The group of teachers with the longer teaching experience (21 years of teaching experience and more) reported greater satisfaction with the collaboration with their colleagues, with a score of 5.04 and a standard deviation of 0.92 . Furthermore, teachers with 11 to 20 years of teaching experience reported slightly less satisfaction, scoring 4.72, with a standard deviation of 0.77 , whereas teachers with up to 10 years of teaching experience are relatively satisfied, scoring 4.52, with a standard deviation of 1.08 (Table 5).

\subsubsection{Trust}

The category of trust includes the last three items of the questionnaire, which are the following: "Within the framework of working in the school, teachers maintain positive work relationships. School teachers demonstrate their commitment to their job with professionalism. Teachers come to school prepared for their lessons". The mean score of teachers' agreement regarding the aforementioned statements, was 5, with a standard deviation of 0.92 (Table 3). This means that teachers believe that there is trust in the relationships with their colleagues. More specifically, regarding the statement "Within the framework of working in the school, teachers maintain positive work relationships", 69.3\% mostly agreed to this point of view, whereas $8 \%$ strongly disagreed. Moreover, regarding the statement "School teachers demonstrate their commitment to their job with professionalism" most teachers seemed to agree to it, compared to $2.6 \%$ who believe that teachers are not committed to their job with professionalism. Finally, the statement "Teachers come to school prepared for their lessons" is received positively by the vast majority of teachers, namely $84 \%$, compared to a percentage of $2 \%$ of them, who expressed strong disagreement to the aforementioned point of view.

Statistically significant differences were found in the trust factor according to teachers' age $\left(\mathrm{F}_{3,121}=2,907, \mathrm{p}<\right.$ 0.001). The LSD test showed that the issue of trust is more intense in the older teacher within a school community. Teachers older than 51 years feel the sense of trust among their colleagues to the greatest extent, reaching a score of 5.33, with a standard deviation of 0.68 . Then follows the age group of teachers aged from 41 to 50 years, who report trust, scoring 5.03 with a standard deviation of 0.82 , whereas teachers aged from 31 to 40 years believe that there is less trust, scoring 4.99 with a standard deviation of 0.92. Finally, the mean score of the age group from 20 to 30 years for trust is 4.52 , with a standard deviation of 0.98 (Table 4).

Regarding the aspect of trust, teachers expressed significantly different views also in terms of their total years of teaching experience $\left(F_{2,135}=3.396, p<0.001\right)$. LSD test revealed that teachers with longer teaching experience perceive trust and commitment to their duty to a much greater extent. Notably, teachers with a teaching experience of more than 21 years seemed to be satisfied enough with respect to their colleagues' trust within the context of their school duties, scoring 5.19 with a standard deviation of 0.69 , whereas teachers with less teaching experience (from 11 to 20 years) report a slightly smaller satisfaction, rating it with 5.01, with a standard deviation of 0.93 . Finally, teachers with up to 10 years of teaching experience report that they are relatively satisfied, scoring 4.74, with a standard deviation of 0.99 (Table 5).

Table 4. Descriptives for each of the seven teamwork characteristics according to teachers' age

\begin{tabular}{|c|c|c|c|c|c|c|c|c|}
\hline \multirow[b]{3}{*}{ Factor } & \multicolumn{6}{|c|}{ Age } & \multirow{2}{*}{\multicolumn{2}{|c|}{$51+$}} \\
\hline & \multicolumn{2}{|c|}{-30} & \multicolumn{2}{|c|}{$31-40$} & \multicolumn{2}{|c|}{$41-50$} & & \\
\hline & $\mathrm{M}$ & SD & $\mathrm{M}$ & $\mathrm{SD}$ & $\mathrm{M}$ & $\mathrm{SD}$ & $\mathrm{M}$ & $\mathrm{SD}$ \\
\hline Communication & 4.4 & 1.1 & 4.9 & 0.9 & 5.0 & 0.8 & 5.3 & 1.0 \\
\hline Leadership & 4.0 & 1.1 & 4.7 & 0.9 & 4.5 & 0.9 & 4.7 & 1.0 \\
\hline Guidance & 3.9 & 1.1 & 4.5 & 1.2 & 4.5 & 1.1 & 4.9 & 1.2 \\
\hline Feedback & 4.2 & 1.0 & 4.6 & 1.1 & 4.6 & 1.1 & 5.0 & 0.8 \\
\hline Supportive Behaviour & 4.4 & 1.1 & 5.1 & 1.1 & 5.0 & 0.9 & 5.6 & 0.6 \\
\hline Collaboration & 4.3 & 0.9 & 4.9 & 1.1 & 4.9 & 0.9 & 5.1 & 1.0 \\
\hline Trust & 4.5 & 1.0 & 5.0 & 0.9 & 5.0 & 0.8 & 5.3 & 0.7 \\
\hline
\end{tabular}

Table 5. Descriptives for each of the seven teamwork characteristics according to teachers' experience

\begin{tabular}{|c|c|c|c|c|c|c|}
\hline \multirow{2}{*}{} & \multicolumn{5}{|c|}{ Years of experience } \\
\cline { 2 - 7 } & \multicolumn{2}{|c|}{-10} & \multicolumn{2}{|c|}{$11-20$} & \multicolumn{2}{c|}{$21+$} \\
\hline Factor & $\mathrm{M}$ & SD & M & SD & M & SD \\
\hline Communication & 4.60 & 1.03 & 4.82 & 0.79 & 5.16 & 0.90 \\
\hline Leadership & 4.31 & 1.06 & 4.33 & 0.85 & 4.75 & 0.83 \\
\hline Guidance & 4.13 & 1.17 & 4.31 & 1.06 & 4.69 & 1.08 \\
\hline Feedback & 4.29 & 1.10 & 4.45 & 0.90 & 4.77 & 1.06 \\
\hline Supportive Behaviour & 4.61 & 1.13 & 4.99 & 0.89 & 5.27 & 0.81 \\
\hline Collaboration & 4.52 & 1.08 & 4.72 & 0.77 & 5.04 & 0.92 \\
\hline Trust & 4.74 & 0.99 & 5.01 & 0.93 & 5.19 & 0.69 \\
\hline
\end{tabular}

\section{Discussion}

The findings of this research indicate that the aspect of communication seems to be affected by the teachers' age and the total years of their teaching experience. The older the teachers' age group becomes and the longer their teaching experience is the greater their satisfaction arising from the communication with their colleagues is while strengthening at the same time their collegial commitment towards the organization. Reference [13] believes that similarities in group members such as age and teaching 
experience increase coherence and lead to goal achievement. Coherently acting groups are effective groups. Effective groups clarify their identity, goals, acceptance and trust. On the other hand lack of collaboration and inflow of new ideas result in low performance and eventually in an inefficient organization [13].

Similarly, the issue of leadership also seems to be affected by the total years of teaching experience. Teachers with more years of teaching experience report more satisfaction from their relationship to the leadership and goals set by the school organization. This may be explained by the fact that teachers with the most years of teaching experience act more collectively and tied more with their colleagues. Those teachers are more committed retain a familiar atmosphere in school while at the same time their team adjustment is vital since it is the foundational building block of commitment between staff and school [15]. School leadership guides the team of teachers towards establishing a spirit of collaboration, open communication and support of teaching with educational activities [39], offers opportunities for greater teaching and pedagogical outcomes to teachers and better learning conditions to students. Leadership maintains the good collegial relationships and defines the actions and goals of the school organization, offering at the same time guidance and support to the team members.

The results of this research demonstrate also that guidance provided to teachers at the school setting by their colleagues is influenced by their total years of teaching experience. It has become clear that teachers with more years of teaching experience seem to perceive guidance by their colleagues to a much greater extent. Commitment [46] grows slowly but steadily over time.

The aspect of feedback as a teamwork component is not significantly influenced by teachers' age or their total years of experience. Feedback involves the giving, seeking, and receiving of information. Giving feedback refers to providing information regarding other team members' performance, while seeking feedback refers to requesting input or guidance regarding performance and receiving feedback refers to accepting positive and negative information about performance [37].

The results of this research lead also to the conclusion that supportive behavior developed between teachers seems to be affected by the age and the total years of teaching experience. It is noticed that in older age groups as well as in teachers with longer teaching experience the support offered by colleagues is perceived to a greater extent which enhancing their commitment to the organization where they work. Complementing and helping each other is undoubtedly vital to teachers in order to achieve the goals set by the school organization. Good interpersonal relationships are considered to be a substantial source of internal reward which becomes meaningful due to the lack of strong external rewards when we refer to the teaching profession and due to the issues often arising in relationships between students and teachers [51]. Modern researches on teachers' work life start from the assumption that colleague relationships help teachers to cope with the multiple demands of their profession reduce stress and increase their satisfaction and their "well-being" in a more effective way. The lack of contact to their colleagues on the contrary makes teachers feel disappointed and bored affecting students in turn in the same way.

It should be pointed-out. that the age as well as the total years of teaching experience influences the extent (level) of collaboration building in the framework of collegial relationships in the school unit. Teachers of the older age groups and respectively those with more years of teaching experience as well as specialist subject teachers report more satisfaction from collaboration with their colleagues. The combination of knowledge and experiences of teachers provides motivation to the organization, in order to set new and higher goals. According to data collected from studies, the high level of teamwork in schools is accompanied by a positive atmosphere collaboration between teachers and high educational performance of students as well as school distinctions collective responsibility for work, assistance offered to colleagues and collaboration lead not only to awareness of the school organization's weaknesses and strengths but also to school success as a whole [39]. Collectivity is defined as the ability to solve problems at collective organizational and individual level. The power of teacher collectivity is expressed through the skills of its members to achieve homogenization.

Collaboration between teachers transforms and changes the school organization, as the school staff gets involved in the process. It influences the teaching task of teachers by building a relationship between teachers. [5,39]. The combination of knowledge and experiences of every individual in the school teachers' teams creates an educational process beyond the technocratic perception of the partial and fragmented approach to handling educational and teaching issues arising in the school organization. Building this relationship among teachers [21] creates a community of teachers which relies on the power of dialogue, tolerance and understanding. A dialectic and interpersonal as well as based on collaboration relationship is created.

Finally, the highly important issue that concerns the aspect of trust seems to be particularly also influenced by the age and the total years of teaching experience. Older teachers with more years of teaching experience a stronger sense of trust among their colleagues. The results of collegial trust are a growing sense of solidarity as well as lack of isolation [25] that guide teachers towards a reciprocal management of school goals in order to handle different issues [24].

At this point it should be highlighted that no particular differences occurred (were noticed) in the employment status of teachers and the characteristics of teamwork (communication. leadership. guidance. feedback. supportive behavior. collaboration and trust). Since the study sample consisted primarily of permanentlyemployed teachers holding statutory posts. Frequent substitution of teachers (with substitute or transferred teachers) leads to lower commitment to school collectivity. One of the characteristics of an effective school is the teaching staff stability as reference [15] point out. It cannot be claimed that a teacher's constant presence in the school and the permanent nature of his/her employment leads to a collective commitment between school teachers. On the other hand, temporary employment and nonconstant presence do not seem to lead to any commitment. Therefore, stability strengthens the school organization 
and serves as a factor of collective commitment. It facilitates communication, collaboration, team, spirit, trust, feedback and commitment of teachers with the school and the function of the team of teachers as a collaborative unit.

To summarize, it should be pointed out that teachers' views about their organizational commitment is significantly influenced by their teaching experience. It is quite obvious that since schools are marked by diversity as to their structure and the organizational values, the school must find ways to adjust appropriately to the needs of its teaching staff. Large-scale and frequent changes in the structure of the teaching staff have negative consequences on school effectiveness [42]. Teachers' substitution leads to lower commitment to the school's collectivity.

\section{References}

[1] Anagnostopoulou, Maria, Interpersonal relationships between teachers and students in the school classroom setting - A theoretical analysis and experience-based approach. Thessaloniki: PhD Thesis/AUTH. School of Philosophy and Education. Department of Education [in Greek], 2004.

[2] Angle, H., \& Perry, J. An empirical assessment of organizational commitment and organizational effectiveness. Administrative Science Quarterly, 26. 1-14, 1981.

[3] Becker, H. S. Notes on the concept of commitment. American Journal of Sociology, 66. 32-40, 1960.

[4] Bryk, A. and Schneider, B., Trust in Schools: A Core Resource for Improvement, Russell Sage Foundation, New York, NY, 2002.

[5] Crow. G. M.. Pounder. D. G. Interdisciplinary teacher teams: context. design. and process. Educational Administration Quarterly. 36 (2). 216-254, 2000.

[6] Dee. J.. Henkin. A.. Singleton. A. Organizational commitment of teachers in urban school. Examining the effects of team structures. Urban Education. 41 (6). 603-627, 2006

[7] Dickinson, T., McIntyre, R., Ruggeberg, B., Yanushefski, A., Hamill, L. and Vick, A., A Conceptual Framework for Developing Team Process Measures of Decision-making Performance (Final Report), Naval Training Systems Center, Human Factors Division, Orlando, FL., 1992.

[8] French, W. and Bell, C., Organizational Development: Behavioral Science Interventions for Organizational Movement, Prentice-Hall, Englewood Cliffs, NJ, 1984.

[9] Gambetta, D., “Can we trust trust?”, in Gambetta, D. (Ed.), Trust: Making and Breaking Cooperative Relations, Basil Blackwell, New York, NY, 1988.

[10] Hackman. R. What makes for a great team? APA on line psychological science agenda. 18 (6). Retrieved on January 10. 2010.

[11] Harrison D, Newman D and Roth P. How Important are Job Attitudes? Meta-analytic Comparisons of Integrative Behavioral Outcomes and Time Sequences, Academy of Management Journal, 49. 305-325, 2006.

[12] Heck. H. R. Teacher effectiveness and student achievement. Investigating a multilevel cross-classified model. Journal of Educational Administration. 47 (2). 227-249, 2009.

[13] Hitiris. L., Organizational behavior, human behavior in organizations and enterprises. Athens: Interbooks [in Greek]., 2001.

[14] Hoffman, J., Sabo, D., Bliss, J. and Hoy, W., "Building a culture of trust”, Journal of School Leadership, 4. 484-501, 1994.

[15] Hoy. W. A.. \& Miskel. C. Educational Administration (6th ed). New York: McGraw- Hill International Edition, 2001

[16] Hoy, W. and Kupersmith, W., "The meaning and measure of faculty trust”, Educational and Psychological Research, 5. 1-10, 1985.

[17] Hoy, W., Tarter, C. and Wiskowskie, L., "Faculty trust in colleagues: linking the principal with school effectiveness", Journal of Research and Development in Education, 26(1). 38-45, 1992.

[18] Hulpia. H.. Devos G. How distributed leadership can make a difference in teachers' organizational commitment? A qualitative study. Teaching and Teacher Education. 26. 565-575, 2010.
[19] Inger. Morton "Teacher Collaboration in Secondary Schools". Center Focus. 2. 1-7, 1993.

[20] Jaros, S., Meyer and Allen Model of Organizational Commitment: Measurement Issues. The Icfai Journal of Organizational Behavior, 6 (4), 1-25, 2007.

[21] Kosmopoulos B. A. Relational Dynamics Education of the Person. Athens: Grigoris [in Greek], 1994.

[22] Kuhnert. K. W.. Vance. R. J. Job insecurity and moderators of the relations between job insecurity and employee adjustment. In Quick.J.C.. Murphy. L.R. \& Hurrell. J.J.J. (Eds). Stress and well being at work. Assessments and interventions for occupational mental health. Washington. D.C.: American Psychological Association, 1992.

[23] Lee.V. E.. Smith. J. B. Collective responsibility for learning and its effects on gains in achievement and engagement for early secondary students. American Journal of Education. 104. 103-147, 1996.

[24] Lee T, Mitchell T, Sablynski C, Burton J and Holtom B. "The Effects of Job Embeddedness on Organizational Citizenship, Job Performance, Volitional Absences, and Voluntary Turnover”, Academy of Management Journal, 47. 711-722, 2004.

[25] Little. J. W. The persistence of privacy: autonomy and initiative in teachers' professional relations. Teachers College Record. 91 (4). 509-536, 1990.

[26] Lortie. Dan C. Schoolteacher: A sociological study. Chicago: University of Chicago Press, 2002.

[27] Louis. K. Effects of teacher quality of worklife in secondary schools on commitment and sense of efficacy. School Effectiveness and School Improvement. 9 (1). 1-27, 1998.

[28] Meyer, J. P. \& Allen, N. J. Organizational commitment: Toward a three-component model. Research Bulletin No. 660. The University of Western Ontario, Department of Psychology, London, 1987.

[29] Meyer, J. P. \& Allen, N. J. The measurement and antecedents of affective, continuance and normative commitment to the organization. Journal of Occupational Psychology, 63, 1-18, 1990.

[30] Meyer J, Becker T and Van Dick R (2006), “Social Identities and Commitments at Work: Toward an Integrative Model”, Journal of Organizational Behavior, 27. 665-683, 2006.

[31] Mitchell T R, Holtom B C, Lee T W, Sablynski C J and Erez M. "Why People Stay: Using Job Embeddedness to Predict Voluntary Turnover”, Academy of Management Journal, 44. 1102-1121, 2001.

[32] Mobley, W., Griffeth, R., Hand, H., \& Meglino, B. Review and conceptual analysis of the employee turnover process. Pychological Bulletin, 86. 493-522, 1979.

[33] Morrow. P. Concept redundancy in organizational research. The case of work commitment. Academy of Management Review. 8. 486-500, 1983.

[34] Mowday, R., Steers, R., \& Porter, L. The measurement of organizational commitment. Journal of Vocational Behavior, 14. 224-247, 1979.

[35] Mowday, R. T., Porter, L. W. \& Steers, R. M. EmployeeOrganization Linkages: The Psychology of Commitment, Absenteeism and Turnover. New York: Academic Press, 1982.

[36] O'Reilly, C. III and J. Chatman. Organizational Commitment and Psychological Attachment: The Effects of Compliance, Identification, and Internalization on Prosocial Behavior. Journal of Applied Psychology, 71 (3). 492-499, 1986.

[37] Park. S.. Henkin. A.. Egley. R. Teacher team commitment. teamwork and trust: exploring associations. Journal of Educational Administration. 43 (5). 462-479, 2005.

[38] Pfeffer, J., \& Lawler, J. Effects of job alternatives, extrinsic rewards, and behavioral commitment on attitude toward the organization: A field test of the insufficient justification paradigm. Administrative Science Quarterly, 25, 38-56, 1980.

[39] Pounder. D. G. Teacher teams: exploring job characteristics and work-related outcomes of work group enhancement. Educational Administration Quarterly. 35 (3). 462-479, 1999.

[40] Reyes. P.. Linking commitment. performance. and productivity. In P. Reyes (Eds.). Teachers and their workplace: Commitment. performance. and productivity. San Francisco: Sage, 1990.

[41] Rusbult, C., \& Farrell, D. A longitudinal test of the investment model: The impact on job satisfaction, job commitment, and turnover of variations in rewards, costs, alternatives, and investments. Journal of Applied Psychology, 68. 429-438, 1983.

[42] Saitis. Ch. Management and Administration in Education. Athens: Self-published [in Greek], 2005a. 
[43] Saitis. Ch. School Management. Athens: Self-published [in Greek], 2005b.

[44] Saraphidou. G. O. Linkages between quantitative and qualitative approaches. The experience-based research. Athens Gutenberg [in Greek], 2011.

[45] Sergiovanni, T. Leadership for the Schoolhouse, Jossey-Bass, San Francisco, CA, 1996.

[46] Smith. P. L.. Hoy. F. Job satisfaction and commitment of older workers in small businesses. Journal of Small Business Management. 30 (4). 106-118, 1992.

[47] Smith, P., Hoy, W. and Sweetland, S. "Organizational health of high schools and dimensions of faculty trust”, Journal of School Leadership, Vol. 11, pp. 135-50, 2001.
[48] Somech. A.. Bogler. R. Antecedents and consequences of teacher organizational and professional commitment. Educational Administration Quarterly. 38. 555-577, 2002.

[49] Tschannen-Moran, M. "Collaboration and the need for trust", Journal of Educational Administration, 39(4). 308-31, 2001.

[50] Vegas. E. Teacher labor markets in developing countries. The Future of Children. 17 (1). 219-232, 2007.

[51] Zahorik. John 'Teachers' Collegial Interaction: An Exploratory Study”. The Elementary School Journal. 87 (4). 385-396, 1987. 